\title{
Endoscopic Third Ventriculostomy for Non-Tumor Obstructive Hydrocephalus in Children under Two Years of Age
}

\author{
Aurélien Ndoumbé1 ${ }^{*}$, Mathieu Motah ${ }^{2}$, Samuel Takongmo ${ }^{3}$ \\ ${ }^{1}$ Faculty of Medicine \& Pharmaceutical Sciences, University of Douala, Douala, Cameroon \\ ${ }^{2}$ Faculty of Medicine \& Pharmaceutical Sciences, University of Douala, Neurosurgeon, Service of Surgery, \\ General Hospital of Douala, Douala, Cameroon \\ ${ }^{3}$ Faculty of Medicine \& Biomedical Sciences, University of Yaoundé I, CHU of Yaoundé, Yaoundé, \\ Cameroon \\ Email: ${ }^{*}$ aurelien.ndoumbe@gmail.com, ${ }^{*}$ aurelen@yahoo.fr
}

Received 6 July 2015; accepted 25 July 2015; published 28 July 2015

Copyright (C) 2015 by authors and Scientific Research Publishing Inc. This work is licensed under the Creative Commons Attribution International License (CC BY). http://creativecommons.org/licenses/by/4.0/

(c) (i) Open Access

\section{Abstract}

The goal of this work is to report on the efficacy of endoscopic third ventriculostomy (ETV) for non-tumor obstructive hydrocephalus in children aged two years and below. In the period between June 2007 and December 2014, we had performed ETV in 30 patients with hydrocephalus from diverse etiologies. Among them were eight children aged two years or below. Clinical, radiological and outcome data of these children were retrospectively reviewed to assess ETV efficiency in this age group. Eight children (6 boys, 2 girls) with age range from 6 to 24 months (mean 12.5 months, median 15 months) suffering from non-tumor obstructive hydrocephalus underwent ETV as primary treatment. Seven patients $(87.5 \%)$ were under two years and 3 had less than one year of age at the time of surgery. Macro crania, suture diastasis, scalp vein bulging and sunset gaze were the most common findings on physical examination. Computed tomography scanning was done in all patients but none had magnetic resonance imaging. Hydrocephalus was due to primary (congenital) aqueductal stenosis in all cases and was associated with myelomeningocele in one. ETV was successful in $7(87.50 \%)$ cases but failed in one. Operation time varied from 28 to 35 minutes (mean 31.12 minutes, median 31.5 minutes). No intraoperative complication occurred. The child in whom ETV failed had postoperative CSF leak. No death related to procedure occurred. Hospital stay ranged from 2 to 4 days (mean, 2.87 days, median, 3 days). Follow up range was 5.5 to 86 months ( 0.46 to 7.16 years); mean, 59.14 months (4.92 years); median, 45.75 months (3.81 years).

${ }^{*}$ Corresponding author.

How to cite this paper: Ndoumbé, A., Motah, M. and Takongmo, S. (2015) Endoscopic Third Ventriculostomy for Non-Tumor Obstructive Hydrocephalus in Children under Two Years of Age. Open Journal of Modern Neurosurgery, 5, $100-105$.

http://dx.doi.org/10.4236/ojmn.2015.53017 


\section{Keywords}

\section{Non-Tumor Obstructive Hydrocephalus, Aqueductal Stenosis, Children under Two Years, Endoscopic Third Ventriculostomy, Cameroon}

\section{Introduction and Background}

Among factors which are believed to influence success rates (SR) of endoscopic third ventriculostomy (ETV), age is still debated [1]-[7]. At the beginning of renewed interest for ETV, age below two years was considered a contraindication [8]. But, as time passed by, this threshold has been lowered and lowered again so that nowadays, many authors do no longer consider age as a limitation factor for ETV [1] [2] [4] [9]. On the other hands, some authors still consider that ETV should not be performed on children younger than six months old, particularly on newborn [8]. On such issue, there will not be class I or class II scientific evidence so that even a small series like this one could contribute to the debate. For that reason, we retrospectively reviewed the cases of children aged two years and below who underwent ETV in our hospital.

\section{Material and Methods}

\subsection{Material}

ETV was performed using the following equipment: ventricular trocar with $6 \mathrm{~mm}$ outer diameter with working, irrigation and aspiration channels, $0^{\circ}$ and $30^{\circ}$ rigid endoscopes with $2.7 \mathrm{~mm}$ outer diameter, grasping and biopsy forceps, micro scissors, bipolar and monopolar coagulation probes, xenon cold light source, one chip standard definition digital camera (Aesculap, Tuttlingen, Germany), an analogic screen (Sony, Tokyo, Japan).

\subsection{Methods}

\section{Study Design and Data Extraction}

It was a retrospective observational study on 8 cases of non-tumor obstructive hydrocephalus in children aged two years and below treated with ETV in our hospital. Data were collected from patients' files and included age, gender, clinical manifestations, imaging data, type, duration and eventual complications of surgery, post-operative clinical and radiological investigations.

Inclusion criteria: children aged two years and under with non-tumor obstructive hydrocephalus treated with endoscopic third ventriculostomy.

Exclusion criteria: children older than two years and adults, children with tumor obstructive hydrocephalus; non-obstructive (communicant) hydrocephalus; non-tumor obstructive hydrocephalus treated with shunt or external ventricular drainage.

Criteria for successful ETV: ETV was considered successful if it alleviated symptoms related to hydrocephalus and achieved shunt independence.

\subsection{Surgical Procedure}

\section{Endoscopic Third Ventriculostomy}

The technique of ETV had been thoroughly described in the medical literature [2] [10]-[13]. All operations were done under general anesthesia with endotracheal intubation.

\subsection{Follow-Up}

Children were hospitalized for 2 to 3 days after ETV. The wound was inspected and dressed daily. Temperature, vital signs, neurological status, or any symptoms were monitored until discharge. The patient in whom CSF leak occurred had unsuccessful lumbar drainage for 3 days; he underwent ventriculo-peritoneal shunt implantation. After discharging from the hospital, patients were seen on consultation at one week, one month, 3, 6, 12 months and then annually after surgery. Clinical symptoms, neurological status and psychomotor development were evaluated. Postoperative CT scan was prescribed to all patients at 3 months after surgery. Parents were informed 
of possible late closure of stoma with the risk of sudden clinical deterioration.

\subsection{Statistical Analysis}

Because of small size of this series, statistical analysis searching for statistically significant differences among age groups was not performed.

\section{Results}

\subsection{Clinical Data}

The study enrolled 8children (6 boys, 2 girls) with age range from 6 to 24 months (mean 12.5 months, median 15 months) suffering from non-tumor obstructive hydrocephalus who had ETV as primary treatment. Seven patients (87.5\%) were under two years and 3 had less than one year of age at the time of surgery (Table 1). Macro crania, suture diastasis, scalp vein bulging and sunset gaze were the most common findings on physical examination (Table 1).

\subsection{Radiological Data}

Computed tomography scan was done in all patients but none had magnetic resonance imaging because it was not available. Hydrocephalus was due to primary (congenital) aqueductal stenosis in all cases and was associated with myelomeningocele in one child (Figure 1). One child only did the postoperative CT scan systematically prescribed to all at 3 months after ETV.

\subsection{Procedures and Outcomes}

All patients underwent ETV as primary treatment. ETV was successful in 7 (87.50\%) cases but failed in one (Figure 2). Operation time varied from 28 to 35 minutes (mean 31.12 minutes, median 31.5 minutes). No intraoperative complication occurred. The child in whom ETV failed had postoperative CSF leak. After three days of unsuccessful external lumbar drainage, he underwent ventriculo-peritoneal shunting. No death related to the procedure occurred. ETV was not repeated due to secondary closure of the stoma.

\subsection{Follow-Up}

Hospital stay ranged from 2 to 4 days (mean, 2.87 days, median, 3 days). Follow up range was 5.5 to 86 months ( 0.46 to 7.16 years); mean, 59.14 months (4.92 years); median, 45.75 months (3.81 years).

\section{Discussion}

\section{ETV Success Rates in Children Less than 2 Years}

Endoscopic third ventriculostomy has been recognized as the first choice treatment for obstructive hydrocephalus

Table 1. Patients' data summary.

\begin{tabular}{|c|c|c|c|c|}
\hline Sex & Age (Mo) & Physical Examination & Complications & ETV outcome \\
\hline $\mathrm{M}$ & 06 & Macrocrania*, suture diastasis, sunset gaze, SVB & No & Success \\
\hline $\mathrm{F}$ & 13 & Macrocrania, suture diastasis, sunset gaze & No & Success \\
\hline M & 07 & Macrocrania, suture diastasis, sunset gaze, SVB & No & Success \\
\hline M & 10 & Macrocrania, suture diastasis, sunset gaze, SVB & CSF leak & Failure \\
\hline M & 14 & Macrocrania, seizures, sunset gaze, hypotonia & No & Success \\
\hline M & 12 & Macrocrania, suture diastasis, sunset gaze, SVB & No & Success \\
\hline $\mathrm{F}$ & 14 & Macrocrania, psychomotor delay & No & Success \\
\hline M & 24 & $\begin{array}{c}\text { Macrocrania, psychomotor delay, sunset gaze, paraplegia, } \\
\text { urinary and fecal incontinence }{ }^{\S}\end{array}$ & No & Success \\
\hline
\end{tabular}

Mo: months. ${ }^{*}$ Head circumference above normal for age and sex +2 standard deviations. SVB: scalp veins bulging. CSF: cerebrospinal fluid. ${ }^{\S}$ Child with lumbosacral myelomeningocele. 


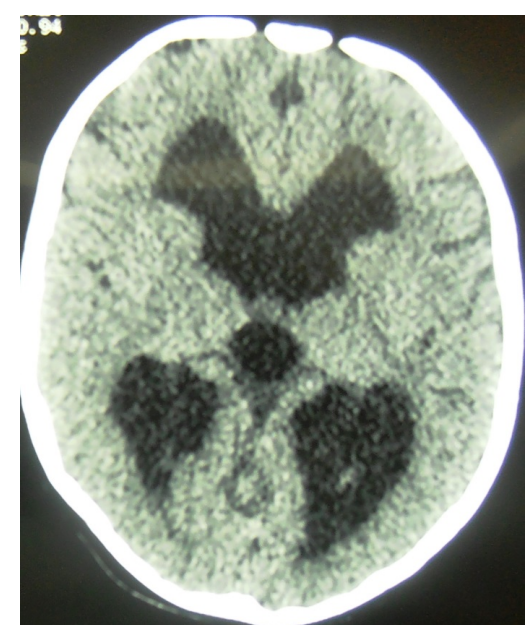

(a)

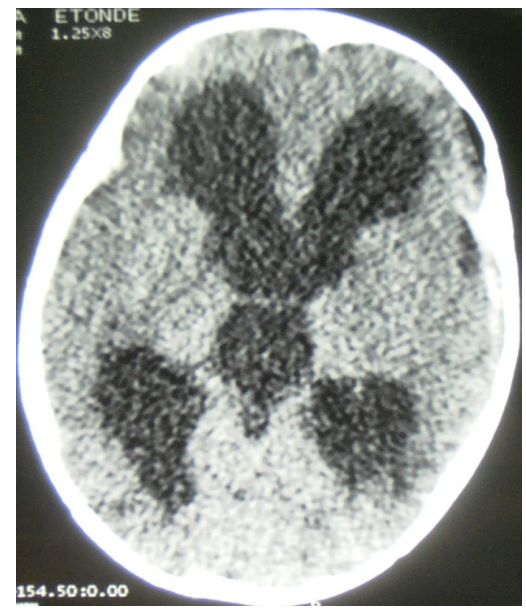

(c)

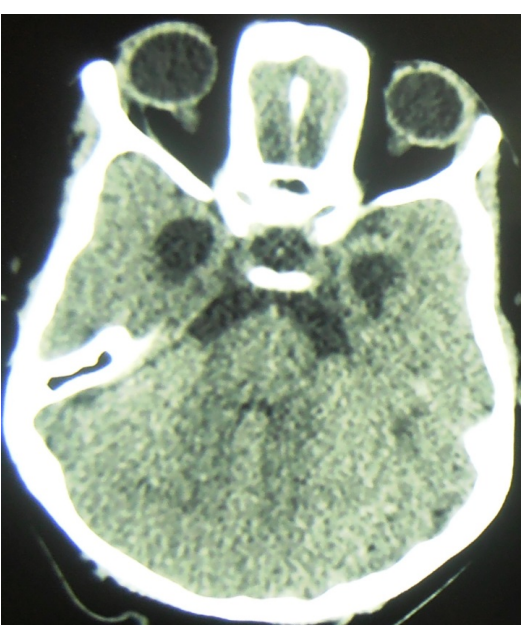

(b)

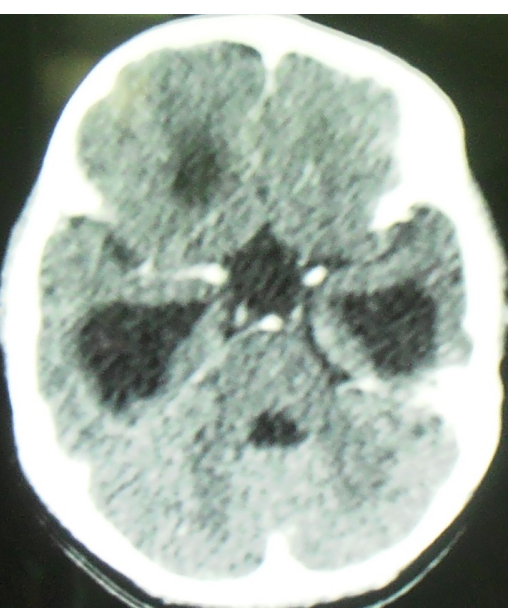

(d)

Figure 1. Computed Tomography scans. (a) Aqueductal stenosis with myelomeningocele, dilated lateral and $3^{\text {rd }}$ ventricles; (b) Same case with normal size $4^{\text {th }}$ ventricle; (c) and (d) Isolated primary aqueductal stenosis with triventricular hydrocephalus.

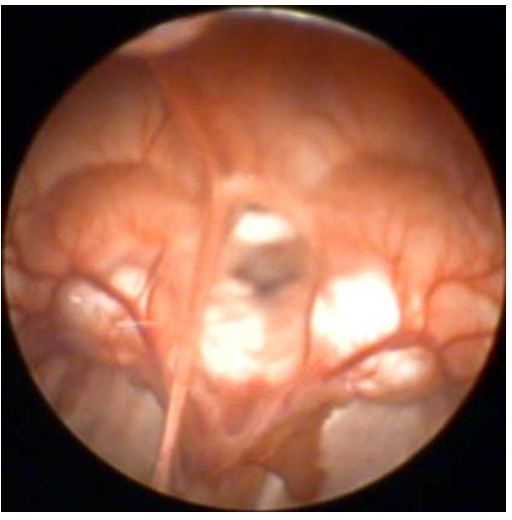

(a)

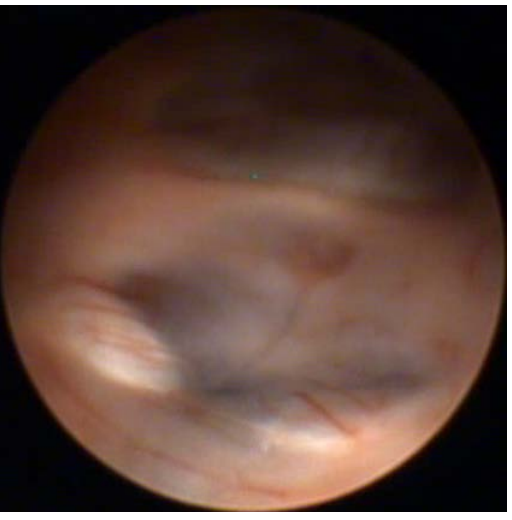

(b)

Figure 2. Endoscopic pictures of failed case. (a) Disorganized intraventricular anatomy with absent septum pellucidum. Caudate nuclei, thalami and $3^{\text {rd }}$ ventricle floor are seen from the lateral ventricle; (b) Same child with thick $3^{\text {rd }}$ ventricle floor, mammillary bodies, tuber cinereum and optic chiasm are seen. 
of diverse etiologies both in adults and children [1] [2] [4] [9] [14] [15].

Performing ETV in children younger than two years old especially below 3 - 6 months and new-born is still debated [3] [6]-[8] [16]. Most studies reporting significant lower success rates of ETV related to age are based on univariate analyses. These studies did not eliminate the possible confounding factors like etiology and type of hydrocephalus which are recognized to influence SR of ETV, with multivariate analyses.

ETV SR reported for infants younger than 2 years range from 33\% [1] [7] [17] to 92.8\% [3]-[6]. The success rate of $87.5 \%$ (7/8) of this series is within that range. In 2005 in Uganda, on a series of 229 children with $81 \%$ of them being less than one year old, Warf BC [17] found that SR of ETV was related to patient age. The SR varied from $40 \%$ to $59 \%$ for children less than one year old and from $81 \%$ to $90 \%$ in children older than one year. But, etiology of hydrocephalus also had strong significant impact on outcome of ETV. Moreover, this series addressed not only obstructive but all types of hydrocephalus as well and SR was significantly lower in children with patent aqueduct (45\%) than in those with aqueductal obstruction (70\%) in the same age group ( $<1$ year). Furthermore, infants with congenital (non postinfectious) hydrocephalus may had have longstanding disease before treatment compared to those with acquired (postinfectious) hydrocephalus as statistical significance related to age was much more stronger for the firsts $(P=0.0002)$ compared to the others $(P=0.0421)$. Therefore, poorer outcome might have revealed the effect of longstanding illness and not impact of age. In the same study, the author drew these conclusions: etiology of hydrocephalus is a more important determinant of ETV success than patient age; young age does not alone prohibit good outcome of ETV; ETV should be the procedure of choice for patient older than one year and in infants less than one year of age with obstructed aqueduct.

In a large prospective series including 550 African children younger than one year, the same author compared success rates of ETV alone versus ETV combined with choroid plexus cauterization (CPC) [18]. ETV-CPC success rates were significantly better than those of ETV alone in children younger than one year, but not in those aged one year and more. In infants less than one year old, ETV-CPC success was also statistically correlated with the cause of hydrocephalus. In 2008, Warf BC also published a series on 115 infants less than one year on ETV-CPC in hydrocephalic patients with myelomeningocele. Overall SR was $76 \%$ and was not related to children's age [19].

Zohdi et al. published a prospective series of 8 cases of infants below six months who underwent ETV as primary treatment of congenital obstructive hydrocephalus. ETV was efficient in one case only and the study was discontinued [16]. In the same way, Helseth et al. in 2000 reported SR of $62 \%$ for patients above 6 months and only an $8 \%$ success for those younger than 6 months of age. They concluded that ETV should not be routinely performed in patients younger than 6 months old [8]. In two series, Furlanetti et al. [6] [7] had found ETV success rates to be related with patients' age (58\% below 6 months of age, 65\% between 6 - 12 months of age and $86 \%$ if age was above one year). ETV was most successful in full term infants than in premature peers. ETV success was associated with age alone but statistical significance was lost when age was assorted with underlying pathology. In patients with aqueductal stenosis, posterior fossa tumors and post hemorrhagic hydrocephalus, there were no statistically significant differences even with univariate analyses.

Many authors had not find age even below six months to be related with ETV success [3] [4] [9] [14]. In a prospective series on 54 patients aged one year or under with 10 having one month or less, Yadav et al. found that age did not impact on the SR of ETV. There was no difference between neonates and other infants. Failure was higher in premature infants than in full-term babies because of low-birth weight but not because of age [3]. Many authors had stated that ETV should be the treatment of first choice regardless of patient's age and etiology of hydrocephalus given that the type of hydrocephalus (obstructive, complex) is appropriate for this technique [1]-[5] [9] [14] [15] [17]-[19]. We share the same view.

\section{Conclusion}

ETV can achieve high success rates for long-term control of obstructive hydrocephalus in children younger than two years old even in the difficult environment of Sub-Saharan Africa. Many series as this one have shown that age should not be a limitation while considering ETV as primary treatment for obstructive hydrocephalus in children. ETV is not efficient in premature and low-weight babies but it has good success rates in full term infants. In Sub-Saharan Africa where shunt dependence is very difficult to manage, ETV should be the treatment of first choice even for children under two years of age with obstructive hydrocephalus. 


\section{Competing Interests}

This work did not receive funding from third parties.

\section{References}

[1] He, Z.H., An, C.X., Zhang, X.D., He, X.D. and Li, Q. (2015) The Efficacy Analysis of Endoscopic Third Ventriculostomy in Infantile Hydrocephalus. Journal of Korean Neurosurgical Society, 57, 119-122. http://dx.doi.org/10.3340/jkns.2015.57.2.119

[2] Yadav, Y.R., Parihar, V., Pande, S., Namdev, H. and Agarwal, M. (2012) Endoscopic third ventriculostomy. Journal of Neurosciences in Rural Practice, 3, 163-173. http://dx.doi.org/10.4103/0976-3147.98222

[3] Yadav, Y.R., Jaiswal, S., Adam, N., Basoor, A. and Jain, G. (2006) Endoscopic Third Ventriculostomy in Infants. Neurology India, 54, 161-163.

[4] Ojo, O.A., Bankole, O.B., Kanu, O.O. and Okubadejo, N.U. (2015) Efficacy of Endoscopic Third Ventriculostomy in the Management of Hydrocephalus in Children under 2 Years of Age: Experience from a Tertiary Institution in Nigeria. Nigerian Journal of Clinical Practice, 18, 318-322. http://dx.doi.org/10.4103/1119-3077.153245

[5] Singh, D., Gupta, V., Goyal, A., Singh, H., Sinha, S., Singh, A. and Kumar, S. (2003) Endoscopic Third Ventriculostomy in Obstructed Hydrocephalus. Neurology India, 51, 39-42.

[6] Furlanetti, L.L., Santos, M.V. and de Oliveira, R.S. (2012) The Success of Endoscopic Third Ventriculostomy in Children: Analysis of Prognostic Factors. Pediatric Neurosurgery, 48, 352-359. http://dx.doi.org/10.1159/000353619

[7] Furlanetti, L.L., Santos, M.V. and de Oliveira, R.S. (2013) Neuroendoscopic Surgery in Children: An Analysis of 200 Consecutive Procedures. Arquivos de Neuro-Psiquiatria, 71, 165-170. http://dx.doi.org/10.1590/S0004-282X2013000300007

[8] Helseth, E., Due-Tønnessen, B., Egge, A., Eide, P.K., Meling, T., Lundar, T. and Frøslie, K.F. (2002) Treatment of Hydrocephalus with Endoscopic Third Ventriculocisternostomy. Tidsskrift for den Norske Laegeforening, 122, 994998.

[9] Santamarta, D., Onzain, I., Blázquez, J.A., Gómez-Moreta, J.A. and Morales, F. (2004) Endoscopic Third Ventriculostomy: Risk Factors for Failure and Evolution of Ventricular Size. Neurocirugia (Astur), 15, 248-256; Discussion 256-257.

[10] Venkataramana, N.K., Rao, S.A.V. and Naik, A.L. (2009) Endoscopic Third Ventriculostomy. Journal of Pediatric Neurosciences, 4, 108-112. http://dx.doi.org/10.4103/1817-1745.57329

[11] Ndoumbé, A., Simeu, C. and Motah, M. (2015) Eight Years of Neuroendoscopy Practice at the University Hospital Center of Yaoundé: Indications, Procedures and Results. Neurochirurgie (under process for publication).

[12] Ndoumbé, A., Simeu, C. and Motah, M. (2015) Non-Tumor Obstructive Hydrocephalus Treated With Endoscopic Third Ventriculostomy in Cameroon. Journal of Korean Neurosurgical Society (under process for publication).

[13] Ndoumbé, A., Simeu, C. and Motah, M. (2015) Tumor Obstructive Hydrocephalus Treated with Endoscopic Third Ventriculostomy in Cameroon. Open Journal of Modern Neurosurgery (Accepted for publication).

[14] Brichtova, E., Chlachula, M., Hrbac, T. and Lipina, R. (2013) Endoscopic Third Ventriculostomy in Previously Shunted Children. Minimally Invasive Surgery, 2013, Article ID: 584567. http://dx.doi.org/10.1155/2013/584567

[15] Idowu, O.E., Falope, L.O. and Idowu, A.T. (2009) Outcome of Endoscopic Third Ventriculostomy and Chhabra Shunt System in Non-Communicating Non-Tumor Childhood Hydrocephalus. Journal of Pediatric Neurosciences, 4, 66-69. http://dx.doi.org/10.4103/1817-1745.57323

[16] Zohdi, A.Z.M., El Damaty, A.M., Aly, K.B. and El Refaee, E.A. (2013) Success Rate of Endoscopic Third Ventriculostomy in Infants below Six Months of Age with Congenital Obstructive Hydrocephalus (a Preliminary Study of Eight Cases). Asian Journal of Neurosurgery, 8, 147-152. http://dx.doi.org/10.4103/1793-5482.121686

[17] Warf, B.C. (2005) Hydrocephalus in Uganda: The Predominance of Infectious Origin and Primary Management with Endoscopic Third Ventriculostomy. Journal of Neurosurgery (Pediatrics 1), 102, 1-15.

[18] Warf, B.C. (2005) Comparison of Endoscopic Third Ventriculostomy Alone with Choroid Plexus Cauterization in Infants Younger Than 1 Year of Age: A Prospective Study in 550 African Children. Journal of Neurosurgery (6 Suppl Pediatrics), 103, 475-481.

[19] Warf, B.C. and Campbell, J.W. (2008) Combined Endoscopic Third Ventriculostomy and Choroid Plexus Cauterization as Primary Treatment of Hydrocephalus for Infants with Myelomeningocele: Long-Term Results of a Prospective Intentto-Treat Study in 115 East African Infants. Journal of Neurosurgery: Pediatrics, 2, 310-316. http://dx.doi.org/10.3171/PED.2008.2.11.310 